Abstract AB0205 - Table 1. Demographics and clinical characteristics $(n=42)$

\begin{tabular}{lccc}
\hline Age (years) & $59 \pm 9$ & \multicolumn{2}{c}{ DMARDs and Biologics } \\
\hline Sex (W/M) & $32 / 10$ & MTX & $15(36 \%)$ \\
Smoking (\%) & $12(29 \%)$ & LEF & $19(45 \%)$ \\
RF(+) & $31(74 \%)$ & ADA & $5(12 \%)$ \\
AntiCCP(+) & $27(64 \%)$ & IFX & $9(21 \%)$ \\
DAS28-ESR & $3.1 \pm 1.0$ & ETA & $10(24 \%)$ \\
Corticosteroids & $28(67 \%)$ & ABA & $13(31 \%)$ \\
& & TOC & $2(5 \%)$ \\
& & TOF & $2(5 \%)$ \\
& & RTX & $20(50 \%)$ \\
\hline
\end{tabular}

Abstract AB0205 Table 2. Thoracic HRCT findings and self-reported questionnaires in RA patients

Warrick Score $(n=15)$

\begin{tabular}{lc}
\hline Alveolitis & $2.6 \pm 1.2$ \\
Fibrosis & $12 \pm 6.3$ \\
Total & $15 \pm 7$ \\
Leicester Cough Questionnaire score $(\mathrm{n}=42)$ & $18 \pm 4$ \\
Modified Borg Scale & $1.8 \pm 2.1$ \\
SF-36 & $53 \pm 17$ \\
\hline
\end{tabular}

Conclusions: In this study, we could not show any relationship between selfreported questionnaires and thoracic HRCT findings, except a weak association of the presence of parenchymal lesions with SF-36 scores. Alveolitis and/or fibrosis on thoracic HRCT were found to be associated with lower DLCO. DLCO was shown to be negatively correlated with SF-36 scores. SF-36 might be included in the detection of pulmonary evaluation in RA patients. The relationship between thoracic HRCT findings and self-reported questionnaires in RA necessitates further studies.

Disclosure of Interest: None declared

DOI: 10.1136/annrheumdis-2018-eular.6158

\section{AB0206 \\ EXPRESSION OF INFLAMMATORY GENES AND THE IL1B GENE ASSOCIATION WITH THE SEVERITY OF RHEUMATOID ARTHRITIS IN TAMIL NADU POPULATION}

B. Vellingiri, A. V, A. I, V. B, D. V, S. C. Human Genetics and Molecular Biology, Bharathiar University, Coimbatore, India

Background: Rheumatoid Arthritis (RA) is a multifactorial complex and chronic inflammatory disease associated with progressive joint destruction, disabling and systemic complications. The prevalence is about $0.5 \%-1 \%$ worldwide and $0.9 \%$ in India. Genetic factors are recognised to have substantial effect on the susceptibility to RA.

Objectives: The present study aims to investigate the inflammatory caspase genes (CASP5 and CASP8) as well as proinflammatory cytokine interleukin1 beta (IL-1 $\beta$ ) in RA patients. Hence the study was designed to explore the possible association of inflammatory genes in Tamil Nadu population.

Methods: We conducted a study involving 55 RA patients and equal number of normal healthy controls and performed gene expression analysis in CASP5 and CASP8 genes. We also carried out genotyping of IL-1 $\beta$ gene using PCR-RFLP. For gene expression study, the mRNA levels of inflammatory genes were assessed using qPCR and the inflammatory marker levels (IL-1 $\beta$ ) were estimated by ELISA.

Results: The gene expression analysis of RA patients showed activation of CASP5 and CASP8 compared to the healthy individuals. The inflammatory marker levels in the serum showed significantly higher levels $(23.35 \pm 2.12 \mathrm{pg} / \mathrm{mL})$ $\mathrm{p}<0.05$ ) in RA patients compared to the control subjects. The homozygous and heterozygous mutant variants of $I L 1 B$ were observed to be higher in the RA patients $(O R=2.1, p<0.01)$.

Conclusions: Thus the results of our study suggests that, the mutant alleles of $I L 1 B$ was associated with RA susceptibility which in turn has direct association with the increased levels of serum IL-1 $\beta$ in RA patients. In addition, the activation of inflammatory genes supports the role of inflammasome in the development of RA in Tamil Nadu population.

\section{REFERENCES:}

[1] Parle M, Kaura, S. How to live with rheumatoid arthritis. Int. Res. J. Pharm 2012;3:115-12.

[2] Huan R, Ting Y, Zhiyong H, Ruiping L, Liqun W. The association between caspase-5 gene polymorphisms and rheumatoid arthritis in a Chinese population. Gene 2018;642:307-312.

[3] Ben Hamad M, Cornelis F, Marzouk S, et al. (2012) Association study of CARD8 (p.C10X) and NLRP3 (p.Q705K) variants with rheumatoid arthritis in French and Tunisian populations. Int J Immunogenet. 39(2): 131-6.
Disclosure of Interest: None declared

DOI: 10.1136/annrheumdis-2018-eular.1896

\section{AB0207 CALPROTECTIN (S100A8/9) PLASMA LEVELS DECREASE AFTER ABATACEPT THERAPY AND CORRELATE WITH DISEASE ACTIVITY IN PATIENTS WITH RHEUMATOID ARTHRITIS}

B. Šumová ${ }^{1,2}$, H. Hulejová ${ }^{1}$, K. Jarošová $^{1,2}$, M. Olejárová ${ }^{1,2}$, S̆$_{\text {. Forejtová }}^{1,2}$, H. Ciferská ${ }^{1,2}$, H. Mann ${ }^{1,2}$, L. Šedová ${ }^{1,2}$, J. Vencovský ${ }^{1,2}$, K. Pavelka $^{1,2}$ L. Šenolt ${ }^{1,2}$. 'Institute of Rheumatology, Prague, Czech Republic; ${ }^{2}$ Department of Rheumatology, First Faculty of Medicine, Charles University, Prague, Czech Republic

Background: Calprotectin (S100A8/9) is a damage-associated molecular pattern molecule that is involved in the early phase of tissue injury. It is found mainly in circulating neutrophils, monocytes and macrophages of rheumatoid arthritis (RA) synovial tissue where it acts as a chemoattractant and induces production of proinflammatory cytokines. Several studies have reported its association with clinical disease activity and radiographic damage in patients with RA.

Objectives: The aim of our study was to analyse the plasma levels of calprotectin in patients with established RA after the abatacept treatment compared with healthy individuals, and to examine their potential association with disease activity and treatment response.

Methods: The plasma levels of calprotectin were determined by ELISA (BÜHL MANN Laboratories AG) in 40 patients with established RA before and 3 months after initiation of abatacept treatment, and in 30 age-/sex-matched healthy subjects. Disease activity was evaluated by 28 -joint Disease Activity Score (DAS28). The CRP levels and erythrocyte sedimentation rate (ESR) were determined by routine laboratory techniques. Data are presented as median $\pm I Q R$

Results: Calprotectin levels at baseline were significantly higher in patients with established RA than in healthy individuals $(1925[741 ; 4093]$ vs. $506[302 ; 754]$ $\mathrm{p}<0.0001 ; \mathrm{ng} / \mathrm{ml})$. After 3 months of therapy, the levels significantly decreased (from $1925[741 ; 4093]$ to $1569[695 ; 3115] \mathrm{p}=0.045 ; \mathrm{ng} / \mathrm{ml}$ ). Calprotectin baseline levels significantly correlated with CRP, ESR and DAS28 at baseline $(r=0.57$ $p=0.0003 ; r=0.56, p=0.0003 ; r=0.40, p=0.014$, respectively), with change in DAS28 over 3 months $(r=-0.54, p=0.001)$ and with change in CRP over $3,6,12$ months $(r=-0.56, p=0.0006 ; r=-0.61, p=0.001 ; r=-0.71, p=0.0001$, respectively). Calprotectin levels at month 3 significantly correlated with ESR at month 3 $(r=0.43, p=0.013)$, CRP levels at month 3 and $6(r=0.39, p=0.27$ and $r=0.43$, $p=0.024$, respectively) and with change in CRP over 12 months $(r=-0.45$, $p=0.023$ ). Change in calprotectin levels over 3 months correlated with the change in DAS28 over 3 months $(r=0.39, p=0.028)$ and with change in CRP over 3,6 and 12 months ( $r=0.48, p=0.004 ; r=0.38, p=0.028 ; r=0.60, p=0.0009$, respectively). Conclusions: We demonstrate here decrease in plasma levels of calprotectin after 3 months of abatacept therapy in patients with established RA, its association with disease activity and disease activity improvement over time.

Acknowledgements: Supported by the project of MHCR for conceptual development of research organisation 00023728, research project SVV 260373.

Disclosure of Interest: None declared

DOI: 10.1136/annrheumdis-2018-eular.6507

\section{AB0208 UNFAVOURABLE CARDIOVASCULAR RISK PROFILE IN MALE PATIENTS WITH RHEUMATOID ARTHRITIS OF LOW DISEASE ACTIVITY}

B. Targonska-Stepniak ${ }^{1}$, M. Biskup ${ }^{2}$, M. Majdan ${ }^{1} .{ }^{1}$ Department of Rheumatology and Connective Tissue Diseases, Medical University of Lublin, Poland, Lublin; ${ }^{2}$ Rheumatology, Regional Outpatient Clinic, Rzeszow, Poland

Background: Rheumatoid arthritis (RA) is associated with the increased cardio vascular (CV) morbidity and mortality, mostly due to accelerating atherosclerosis Both traditional and non-traditional factors seem to contribute to the excess of CV risk. Data in literature indicate a positive association between RA activity and the extent of CV disease (CVD) risk, suggesting a dominant effect of systemic inflammation. It is reported, that low disease activity is sufficient to achieve a protective effect against CVD and that atherosclerosis is not accelerated in RA of low activity or remission.

Objectives: The goal of the study was to assess CV parameters in female and male patients with RA of low disease activity in comparison with healthy controls. Methods: The study was conducted in 70 patients with low RA activity, without known CVD (54 women, 16 men) and 33 healthy volunteers (18 women, 15 men). Patients underwent standard physical examination, assessment of disease activity in 28 joints (DAS28) and laboratory measurements including amino-terminal pro-brain natriuretic peptide (NT-proBNP). The following procedures were performed both in RA patients and controls: blood pressure (BP), carotid intima 
media thickness (CIMT), electrocardiography (ECG) and echocardiography with assessment of ejection fraction (EF) and diastolic dysfunction (E/A ratio).

Results: The significant differences between male vs female RA patients included: higher mean values of cIMT $[0,93(0,19)$ vs $0,80(0,22) \mathrm{mm}, \mathrm{p}=0,04]$, atherogenic index $[4,2(1,4)$ vs $3,5(1,0), p=0,03]$ and SCORE $[5,7(3,7)$ vs 2,8 $(2,7), \mathrm{p}<0001]$; as well as lower concentration of HDL-cholesterol [(50,2 (12) vs $\left.59^{14,6} \mathrm{mg} / \mathrm{dl}, \mathrm{p}=0,04\right]$ and NT-proBNP $[66,6(61,2)$ vs $106,8(61,5) \mathrm{pg} / \mathrm{ml}, \mathrm{p}=0006]$. The mean values of age, disease duration, DAS28, C-reactive protein, body mass index, BP, QTc, E/A and EF were not significantly different in male and female patients with RA of low activity.

In the control group no significant differences were observed between male and female subjects, when considering: age, cIMT, BP, QTc, EF, E/A

All the male RA patients had features of subclinical or advanced atherosclerosis (cIMT $\geq 0.6 \mathrm{~mm}$ ), there were no male patients with normal cIMT $(<0,6 \mathrm{~mm})$. In controls normal cIMT was found in $5(33,3 \%)$ and subclinical atherosclerosis in 10 $(66,7 \%)$, there was no control subject with advanced atherosclerosis $(p=0,01)$. The mean age of patients and controls did not differ significantly.

Conclusions: The results of the study suggest an unfavourable $\mathrm{CV}$ risk profile in male RA patients with low disease activity. The higher CV risk was observed in male RA patients in comparison with both controls of comparable age, as well as with female RA patients of comparable age, disease duration and activity. It seems that the male gender contributes considerably to $\mathrm{CV}$ risk in the period of low RA activity.

Disclosure of Interest: None declared

DOI: 10.1136/annrheumdis-2018-eular.3142

\section{AB0209 OPTIMISATION OF ULTRASONOGRAPHIC EXAMINATION FOR THE DIAGNOSIS OF EROSIVE RHEUMATOID ARTHRITIS VERSUS EROSIVE OSTEOARTHRITIS WITH RADIOGRAPHY CONSIDERED AS GOLD STANDARD}

C. Roux ${ }^{1}$, F. Gandjbakhch ${ }^{2}$, A. Pierreisnard ${ }^{2}$, M. Couderc ${ }^{3}$, C. Lukas $^{4}$, R. Masri ${ }^{5}$, J.-P. Sommier ${ }^{1}$, I. Clerc-Urmes ${ }^{6}$, C. Baumann ${ }^{6}$, I. Chary-Valckenaere ${ }^{1}$,

D. Loeuille ${ }^{1} .{ }^{1}$ Rheumatology, University Hospital of Nancy, Vandoeuvre-lès-Nancy; ${ }^{2}$ Rheumatology, Academic Hospital Pitie Salpêtrière, Paris; ${ }^{3}$ Rheumatology, University Hospital of Clermont- Ferrand, Clermont- Ferrand; ${ }^{4}$ Rheumatology, University Hospital of Lapeyronie, Montpellier, ${ }^{5}$ Rheumatology, University Hospital of Nancy, Vandoeuvre-lès-Nancy; ${ }^{6}$ Platform of Clinical Research Support PARC, University Hospital of Nancy, Vandoeuvre-lès-Nancy, France

Background: Rheumatoid arthritis (RA) is the most prevalent chronic inflammatory joint disease ${ }^{1,2}$ responsible for structural damage. Radiography $(R X)$ is considered as the gold standard for visualising and quantifying bone lesions in RA. ${ }^{3}$ Musculoskeletal ultrasound (US) is booming in clinical practice for the diagnosis of RA. US can detect more erosions than RX at the joint level, especially at an early stage of the disease. ${ }^{4}$

Objectives: To determine thresholds and better scenarios for the diagnosis of erosive RA by US in RA and osteoarthritic (OA) patients.

Methods: Patients fulfiling ACR 1987 and/or ACR/EULAR 2010 criteria for RA or hand OA criteria were prospectively included. A modified Sharp erosion score was assessed by two blinded readers and one adjudicator for discordant cases (number of eroded joints $\leq$ three). Erosions in US were scored on six bilateral joints (MCP2-3, 5; MTP2-3,5) with a four-grade scale.

Results: A total of 168 patients were included: 122 RA (32 early RA $<2$ years; 90 late $R A \geq 2$ years); 46 OA patients. On RX: 42 RA patients ( 6 early; 36 late) and 5 OA patients were eroded according to ACR/EULAR 2013 criteria (sensitivity: $34.4 \%$, specificity: $89.1 \%$ ). On US, 95 RA patients (21 early; 78 late) and 12 OA patients were eroded. Considering at least two joint facets eroded (threshold 1) or at least one joint facet eroded at grade 2 (threshold 2), sensitivities were good $(68 \%-$ $72.1 \%)$ and specificities excellent $(89.1 \%-100 \%)$. With only six targeted joint facets examined, 73 and 74 patients were classified as erosive RA with threshold 1 and 2 with good sensitivities $(59.8 \%-60.0 \%)$ and excellent specificities $(95.6 \%-$ $100 \%)$ respectively. For all scenarios, agreement between RX and US for the diagnosis of erosive RA was excellent ( $88.1 \%$ to $92.8 \%$ ).

Conclusions: US erosion assessment of six targeted joint facets permitted to detect 1.7 times more erosive RA patients than RX in late and early RA.

\section{REFERENCES:}

[1] Guillemin F, et al. Prevalence of rheumatoid arthritis in France: 2001. Ann Rheum Dis. 2005 Oct;64(10):1427-30.

[2] Alamanos $Y$, et al. Incidence and prevalence of rheumatoid arthritis, based on the 1987 American College of Rheumatology criteria: a systematic review. Semin Arthritis Rheum. 2006 Dec;36(3):182-8.

[3] Baillet A, et al. Comparison of the efficacy of sonography, magnetic resonance imaging and conventional radiography for the detection of bone erosions in rheumatoid arthritis patients: a systematic review and metaanalysis. Rheumatol Oxf Engl. 2011 Jun;50(6):1137-47.
[4] Wakefield RJ, et al. The value of sonography in the detection of bone erosions in patients with rheumatoid arthritis: a comparison with conventional radiography. Arthritis Rheum. 2000 Dec;43(12):2762-70.

Disclosure of Interest: None declared DOI: 10.1136/annrheumdis-2018-eular.2838

\section{AB0210 CLINICAL AND MUSCULOSKELETAL ULTRASOUND ASSESSMENT OF THERAPEUTIC RESPONSE TO TOFACITINIB IN PATIENTS WITH RHEUMATOID ARTHRITIS: REAL-WORLD CLINICAL EXPERIENCE FROM A SINGLE CENTRE IN HONG KONG}

C.K.-L. Yu. Hong Kong Autoimmune and Rheumatic Diseases Certre, Hong Kong, Hong Kong

Background: Increasingly, musculoskeletal ultrasound (MSUS) has been demonstrated as an effective method for monitoring disease activity and joint damage in patients with rheumatoid arthritis (RA).

Objectives: The objective of this single-centre, 12 week study was to evaluate the effects of tofacitinib therapy in Chinese patients with RA using clinical, laboratory and sonographic assessments, with the view to identifying factors that may predict response to tofacitinib. Furthermore, the study sought to determine whether MSUS would be comparable to conventional techniques for monitoring disease activity in RA

Methods: Patients with RA ( $n=18$ ) were treated with tofacitinib $5 \mathrm{mg}$ bd for 12 weeks. Clinical, laboratory and ultrasound examinations were conducted at baseline (T0), and weeks 4 (T1), 8 (T2) and 12 (T3). Erythrocyte sedimentation rate, C reactive protein, physician and patient visual analogue scale for disease activity, number of tender and swollen joints, Clinical Disease Activity Index (CDAI), Simple Disease Activity Index (SDAI) and Disease Activity Score in 28 joints (DAS28) were assessed and compared. MSUS was performed bilaterally in all metacarpophalangeal, interphalangeal, wrist and knee joints. A semi-quantitative score (03) was used to indicate the presence of a localised inflammatory process and/or structural damage. The cumulative total was used as an indicator of global change in each joint (single joint score). The sum of the single joint scores was used as an indicator of overall polyarticular involvement in each patient (total joint score).

Results: Of the 18 patients recruited into the study, all 18 were examined at T0, $\mathrm{T} 1$ and $\mathrm{T} 2$, and 17 patients were evaluated at T3. All clinical and laboratory measures, as well as MSUS scores, were significantly reduced during follow-up. There was a significant correlation between MSUS scores and conventional (clinical and laboratory) measures of disease activity. Correlation coefficients between the techniques and factors potentially predicting response to tofactinib will be reported.

Conclusions: A positive response to tofacitinib treatment was shown by both MSUS examination and clinical evaluation, with good correlation between the methods. In a busy, every-day, clinical-practice setting in Hong Kong, MSUS was found to be a useful tool for monitoring and following-up the effects of biologic therapy in RA, for the assessment of both inflammatory and destructive changes.

Disclosure of Interest: None declared

DOI: 10.1136/annrheumdis-2018-eular.5054

\section{AB0211 THE RELATIONSHIP BETWEEN THE ELEVATED SERUM IMMUNOGLOBULIN G4 LEVEL AND DISEASE ACTIVITY IN PATIENTS WITH RHEUMATOID ARTHRITIS}

C.-N. Son, H.-J. Jeong, J.-N. Chae, J.-M. Kim, S.-H. Kim. Internal Medicine, Keimyung University, Daegu, Korea, Republic of Ireland

Background: High levels of serum immunoglobulin G4 (IgG4) would comprise a useful diagnostic tool in lgG4-related disease, but little information is available about IgG4 in conditions other than IgG4-related disease, including rheumatic diseases. Previous studies indicate that the elevated serum IgG4 in rheumatoid arthritis (RA) is common and disproportional to total lgG.

Objectives: The aim of study is to evaluate the level of serum lgG4 and lgG4/total IgG ratio in patients with $R A$

Methods: Ninety-six patients with RA and one hundred and thirty-five non-RA controls were enrolled between March 2014 and July 2017. All samples were collected before the treatments. The levels of Serum total $\lg G$ and $\lg G 4$ were deter mined by nephelometric assay. The cut-off value of serum IgG4 was $135 \mathrm{mg} / \mathrm{dL}$. Data on clinical variables and disease activity markers, such as numbers of tender and swollen joints, levels of acute phase reactants and disease activity score 28 (DAS28) were recorded in RA patients. We compared the levels of serum IgG4 and the ratio of $\operatorname{lgG} 4 /$ total $\operatorname{lgG}$ in rheumatoid arthritis with healthy controls and other rheumatic diseases. This study also investigated the difference the relationship between levels of serum IgG4 and disease activity in RA. 